\title{
MONITORIZAÇÃO DA FORÇA DA ONDULAÇÃO NA BASE DA ARRIBA (PESSEGUEIRO, SW PORTUGAL). PRIMEIROS RESULTADOS ${ }^{1}$
}

MÁRIO NEVES ${ }^{2}$

\begin{abstract}
Resumo - Neste artigo descrevem-se brevemente as características de um novo sensor da força da ondulação (EWIN) instalado na plataforma rochosa litoral do Pessegueiro, numa experiência piloto em Portugal. São igualmente analisados alguns dos primeiros resultados obtidos, em particular os registos de força máxima, bem como as características da ondulação que lhes deram origem.
\end{abstract}

Palavras-chave: Sensor da força da ondulação, Pessegueiro (Portugal)

Abstract - Measurement of the Wave Force at the Cliff Base (Pessegueiro, SW PORTUGAL). FIRST RESULTS. In this article the characteristics of a new wave force sensor (EWIN) are briefly described. This instrument was bolted to the shore platform of Pessegueiro on a first trial experience in Portugal. The maximum wave force records are also analysed in correlation with the wave climate occured in these occasions.

Keywords: Wave force sensor, Pessegueiro (Portugal)

A dinâmica de evolução dos vários tipos de litoral está dependente de um vasto conjunto de factores cuja interacção condiciona os processos predominantes em cada local.

Dentro deste conjunto, o factor activo mais importante é seguramente o clima de agitação marítima. Assim, a ondulação é a responsável pelo recuo de grande parte dos litorais rochosos, pelo transporte de sedimentos e pela sua acumulação nos locais mais abrigados.

No caso particular dos litorais rochosos, o conhecimento da importância da ondulação na sua evolução não basta. Torna-se necessário quantificar o peso deste

1 Contribuição do Grupo DISEPLA.

2 Assistente da Universidade de Lisboa. Investigador do CEG, Centro de Estudos Geográficos, Faculdade de Letras de Lisboa, 1699 Lisboa Codex. Tel: (351-1)7940218; Fax: (351-1) 7938690; E-mail: mario.neves@ceg.ul.pt. 
factor quando confrontado com o conjunto dos restantes. Pelo menos cinco aparelhos terão sido desenvolvidos com o objectivo de determinar a força da ondulação na faixa de rebentação (WILLIAMS e ROBERTS, 1995), nem todos, porém, bem sucedidos. Ao que se sabe, nenhum foi utilizado em Portugal.

Um aparelho deste tipo, criado pelo Prof. Guto Roberts, da Universidade de Glamorgan, no País de Gales, por ele designado EWIN (termo galês que se refere à faixa de ressaca), foi instalado pela primeira vez em Portugal, em 1994, inserido no âmbito do Projecto Calma ${ }^{3}$.

O EWIN (fig. 1) consiste basicamente num sensor que, em conjunto com um circuito amplificador alimentado por uma bateria, permite registar, num computador, um sinal proporcional à força aplicada nesse sensor. A Unidade de Força utilizada é o Newton $(\mathrm{N})$, e o aparelho permite registos até $400 \mathrm{~N}$, com uma resolução, nos valores mais baixos, de cerca de 0,2 N (WILLIAMS e ROBERTS, 1995). Todo este conjunto se encontra no interior de um contentor estanque, de aço, que é fixado à plataforma rochosa litoral. O EWIN fica submerso unicamente aquando da maré alta, permitindo, deste modo, a recolha das informações registadas e efectuar nova programação na baixamar.

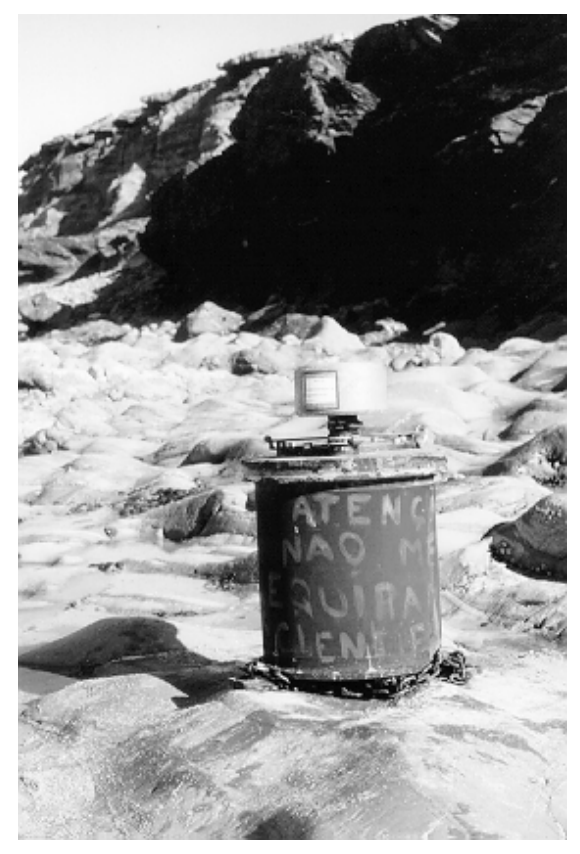

Fig. 1 - O EWIN fixado à plataforma rochosa litoral.

\footnotetext{
3 Projecto CALMA (Conhecimento dos Ambientes Litorais e Marinhos do Alentejo), JNICT/PEAM/ /C/CNT/56/91.
} 
O programa de computador liga o aparelho durante parte da maré alta, não efectuando, de momento, leitura contínua de dados superior a um minuto. Estão previstos quatro tipos de rotinas com períodos de um minuto ligado e um, dois, cinco ou dez minutos desligado, com o objectivo de, não só limitar o número de registos a analisar, como também diminuir o gasto de energia necessária ao funcionamento do aparelho, permitindo, deste modo, prolongar o período global de observação. O software permite ainda escolher a frequência de registo (função dos objectivos pretendidos e da memória disponível). Assim, a frequência pode ser de 120, 60, 30 e $15 \mathrm{~Hz}$. Somente nos dois primeiros, o impacto dos fragmentos rochosos pode ser claramente identificado; no entanto, os seus registos necessitam de maior memória disponível.

O EWIN foi instalado na plataforma rochosa litoral do Pessegueiro, desde meados de Setembro de 1994 até ao princípio de Abril de 1995. Os testes de afinação do sistema decorreram durante o primeiro mês após a instalação, tendo-se obtido registos completos entre 16/10/94 e 25/11/94, e entre 6/12/94 e 31/3/95 (a falha entre $25 / 11$ e $6 / 12$ de 1994 , deveu-se a avaria de um dos componentes do sistema).

Considerando as restrições de bateria e de memória do computador, o sensor foi programado para obter registos da força da ondulação de uma hora antes até uma hora depois de todas as preia-mares, por períodos de um minuto ligado e dez desligado, para uma frequência de registo de $30 \mathrm{~Hz}$.

Nesta primeira abordagem aos resultados obtidos, pretendia-se correlacionar a força da ondulação com o efeito morfogenético que poderia ocorrer neste troço de litoral (NEVES, 1995 e 1996). Optou-se assim por utilizar os valores de força máxima registados em cada minuto. Por cada situação de preiamar, calculou-se então a força máxima média e a força máxima absoluta. Finalmente, construiram-se gráficos com estes dois parâmetros.

Tendo sido igualmente a primeira vez que se instalou este aparelho por período tão longo, não existem por isso outros registos de força da ondulação similares, com os quais se possam efectuar comparações. Tentou-se, apesar de tudo, correlacionar os resultados obtidos com a altura significativa e o período médio das ondas, parâmetros calculados com base nos registos de uma bóia instalada ao largo de Sines pelo Instituto Hidrográfico. Infelizmente esta bóia funcionou irregularmente neste Inverno. De entre os períodos com informação comum EWIN/bóia, seleccionei o período de 14/2/95 a 31/3/95, por ser aquele onde o clima de agitação marítima foi superior (fig. 2).

Se considerarmos a altura significativa das ondas medida na bóia de Sines, neste Inverno não houve situações de tempestade importantes, razão pela qual a acção morfogenética das ondas foi muito reduzida. Apesar de tudo, é possível analisar os resultados e deles extrair algumas conclusões. 


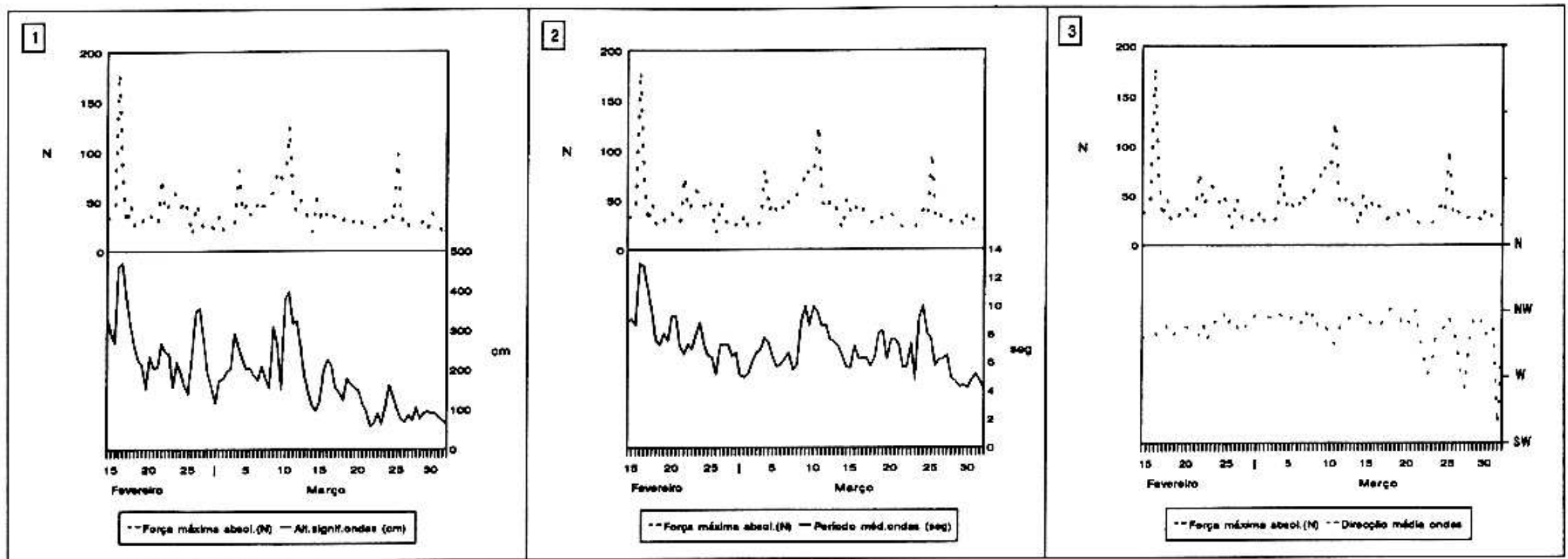

Fig. 2 - Comparação entre os valores de força máxima absoluta calculados com base nos registos do EWIN e alguns parâmetros que caracterizam a agitação marítima (bóia de Sines), no período de 14/2/95 a 31/3/95. 
Dentro dos valores de força máxima absoluta registados no período de 14/2/95 a 31/3/95, três situações ressaltam: as ocorridas em 16/2, 10/3 e 25/3.

Considerando todas as observações efectuadas no Outono/Inverno de 1994/95, foi na preiamar das 3h 50m do dia 16 de Fevereiro de 1995 que se registou o pico de força máxima, atribuível à ondulação, com $181 \mathrm{~N}^{4}$. Como se pode verificar pelos gráficos da fig. 2, este registo ocorreu num dia de relativamente elevada agitação marítima, em que a altura significativa das ondas se situou entre os 4 e os 5 metros, com a altura máxima a ultrapassar mesmo os 7 metros $(7,29 \mathrm{~m})$, sendo a ondulação proveniente de $\mathrm{WNW}\left(\mathrm{N} 301^{\circ}\right)$. O mais elevado período médio da onda foi também alcançado neste dia, com 13 segundos. Infelizmente, devido a algumas falhas no software do EWIN, o gráfico representando as forças aplicadas durante o minuto em que ocorreu este pico não se encontra disponível.

No dia 10 de Março de 1995 (na preiamar das 22h 41m), foi registado o segundo mais importante pico de força da onda $-125,6 \mathrm{~N}$. Neste caso, a ondulação, proveniente como no caso anterior, de $\mathrm{WNW}\left(\mathrm{N} 293^{\circ}\right)$, apresentava oscilações. O registo das ondas significativas apresenta oscilações consideráveis entre 1,5 e 4 metros (com a altura máxima a atingir 7,21 m), para um período de 9,6 segundos. Curiosamente, corresponde este pico a uma ligeira e pouco duradoura modificação da origem da ondulação, que nos dias anteriores provinha de NW $\left(\mathrm{N} 308^{\circ}\right.$ a N312 ${ }^{\circ}$ ) e no dia 10 passou a ter origem no rumo WNW $\left(\mathrm{N} 293^{\circ}\right)$, voltando ao rumo NW nos dias seguintes. A conjugação desta informação com a referente à altura das ondas, e com a análise da situação sinóptica do Atlântico oriental, permite concluir que as oscilações apontadas para este parâmetro deverão estar relacionadas com o cruzamento de, pelo menos, dois tipos de ondulação: um primeiro, mais duradouro, proveniente de NW, com reduzida altura significativa da onda; e um segundo, que corresponde a um episódio efémero, mas com um clima de agitação marítima mais significativo, que proveio de WNW, e que só se fez sentir no dia 10 de Março.

Como se pode observar na fig. 3, a onda que provocou o pico de força registado aparece no meio de ondas de força muito reduzida. Os dois picos em que se subdivide o fluxo são comuns a outras observações, e podem ficar a dever-se a características internas de progressão da onda, ou às modificações nesta progressão introduzidas pelas particularidades do litoral.

\footnotetext{
${ }^{4}$ Foi ainda registado um valor superior de 235,6 N, no dia 23 de Janeiro de 1995; no entanto, este valor aparece isolado no meio de registos fracos (11 a $21 \mathrm{~N}$ ), o impacto é pontual, não se estendendo por alguns segundos como ocorre com os registos normais das ondas e, facto mais importante, não se verifica praticamente refluxo $(<15 \mathrm{~N})$; não apresenta, deste modo, características que o permitam classificar como resultante da força das ondas, podendo estar relacionado com o impacto de um objecto pesado, como um tronco, por exemplo.
} 


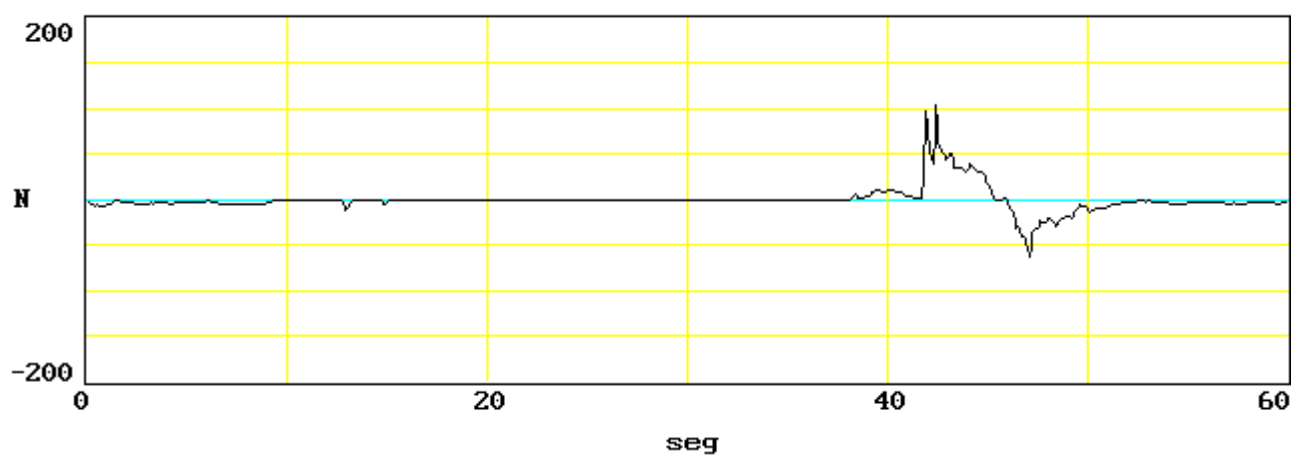

Figura 3 - Registo da força da ondulação pelo EWIN na preiamar das 22h 41m do dia 10 de Março de 1995

Finalmente, no dia 25 de Março, ocorre novo pico de força das ondas, este mais reduzido $(97,5 \mathrm{~N})$. Neste caso, a altura significativa das ondas era muito fraca (1 metro), com um período de 7,7 segundos. Relativamente à direcção da ondulação, observa-se uma situação idêntica à anterior, pois o rumo das ondas, neste dia, NW $\left(\mathrm{N} 312^{\circ}\right)$, está entre dois períodos em que a ondulação chegou a ser de W $\left(\mathrm{N} 272^{\circ}\right)$. A fraca altura das ondas poderá ter permitido que alguma possa ter sofrido rebentação exactamente sobre o sensor, justificando assim o valor registado (fig. 4). A ser exacto, este facto demonstra que, embora não deixe de se reconheçer a enorme capacidade morfogenética das grandes tempestades, também as situações de inferior altura da onda podem originar impactos fortes na base da arriba.

Por último, resta referir que, apesar do relativo pioneirismo da experiência impedir a comparação com outros locais ou anos, podemos classificar o período de observações, com base na análise das características da ondulação recolhidas no ondógrafo de Sines, como um período em que, globalmente, o mar se apresentou pouco agitado, sendo pontuais as situações em que a altura significativa das ondas ultrapassou o limite da tempestade dos 5 metros. Deste modo, é possível esperar valores superiores aos obtidos para a força da ondulação, num ano em que ocorram as tempestades que normalmente caracterizam esta costa. 


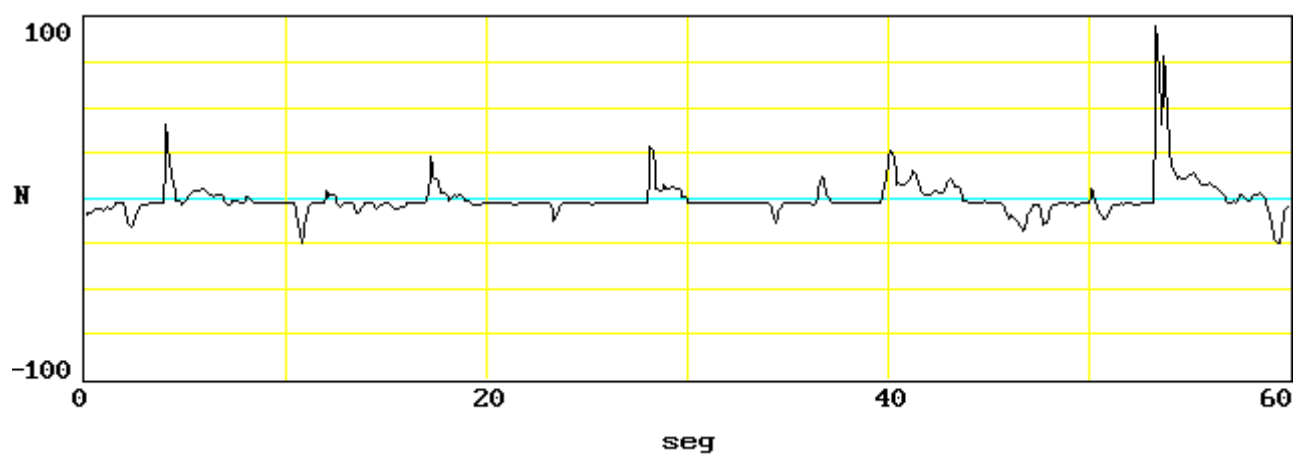

Fig. 4 - Registo da força da ondulação pelo EWIN na preiamar das 10h 57m do dia 25 de Março de 1995.

Neste estádio de investigação, é essencial modificar o tipo de registos efectuados pelo EWIN, de forma a obter uma monitorização continuada. Isto iria seguramente clarificar as características das ondas que atingem o aparelho e consequentemente a base da arriba onde ele está instalado. Será igualmente necessário desenvolver e instalar outros aparelhos idênticos, que permitam efectuar comparações espaciais da força das ondas, o que poderá ser fundamental na determinação dos factores responsáveis por essas diferenças.

\section{BIBLIOGRAFIA}

NEVES, M. (1995) - Dinâmica actual e recente dos litorais rochosos. Exemplos do SW português. Dissertação de Mestrado em Geografia Física e Ambiente, Lisboa, 127 pp.+anexos.

NEVES, M. (1996) - Rock coast of Pessegueiro (SW Portugal). Present-day evolution. In A. B. Ferreira \& G. T. Vieira (eds.), Fifth European Intensive Course on Applied Geomorphology - Mediterranean and Urban Areas, Departamento de Geografia, Universidade de Lisboa, 211-214.

WILLIAMS, A. T.; ROBERTS, G. T. (1995) - The measurement of pebble impacts and wave action on shore platforms and beaches: the swash force transducer (swashometer). Marine Geology 129, p. 137-143. 